\title{
Observations on a Model of Proliferative Lung Disease
}

\author{
II. DESCRIPTION OF PULMONARY GAS EXCHANGE \\ AND COMPARISON OF FICK AND DYE CARDIAC OUTPUTS
}

\author{
P. R. B. Caldwell, U. Echeverri, M. M. Kilcoyne, and H. W. Fritts, JR. \\ From the Department of Medicine, College of Physicians $\mathcal{E}$ Surgeons, \\ Columbia University, New York, New York 10032
}

\begin{abstract}
A B S T RACT Measurements of gas exchange in dogs with granulomatous lung disease resembled those which have been made in similar disorders of man. The minute volume of ventilation was large, the oxygen extracted from each liter of ventilation was low, and the arterial blood oxygen saturation tended to be subnormal despite hyperventilation. When the diseased dogs breathed $21 \%$ oxygen and had alveolar oxygen tensions above $100 \mathrm{~mm}$ $\mathrm{Hg}$, the pulmonary blood flows calculated from the Fick principle were significantly higher than those estimated by the dye-dilution method. By way of contrast, the two values agreed when the alveolar tensions were lowered. Whether the agreement of the flows is causally related to the alveolar tension remains an open question. A possible explanation may lie in the effect of alveolar tension on the oxygen consumed by the diseased lung.
\end{abstract}

\section{INTRODUCTION}

Most in vivo studies of lung metabolism have focused attention on the transpulmonary arteriovenous $(A-\bar{V})$ difference of lactatae and on the implication this difference holds for the calculation of blood flow by the Fick principle. In brief, the implied relation between lactate and flow has been described in the following ways: the Fick value rests on the premise that the oxygen utilized by the pulmonary tissues is a negligible fraction of the total oxygen consumption; further, a disappearance of lactate from the blood perfusing the lung might signify an oxidation of this compound by the pulmonary tissues; and finally, such oxidation could increase the intrapulmonary consumption of oxygen to the point where the

This work was presented as a preliminary report. Caldwell, P. R. B., U. Echeverri, and H. W. Fritts, Jr. 1967. Metabolic behavior of lung disease. Trans. Assoc. Amer. Physicians Philadelphia. 80: 97.

Received for publication 5 May 1969 and in revised form 3 March 1970. first premise would become invalid, causing the Fick value to be falsely high (1). As it stands, there is little evidence to suggest that the effect has practical importance. Transpulmonary differences of lactate have, with few exceptions, been small and random in direction with average values close to zero (1-5).

In contrast to these earlier observations, recent studies on dogs with granulomatous lung disease have revealed a predictable pattern of $A-\overline{\mathrm{V}}$ lactate differences (6). When the diseased dogs breathed $21 \%$ oxygen, the average $A-\bar{V}$ difference of lactate was near zero; but when they breathed an hypoxic mixture, their $A-\overline{\mathrm{V}}$ differences widened in the direction of lactate production. While these differences were opposite to those considered by earlier writers, the combination of eupoxic and hypoxic responses provided an opportunity to examine the relation of lactate to the agreement of the Fick and dye flows.

The first purpose of this paper is to describe the pulmonary gas exchange in the dogs with granulomatous disease; the second purpose is to present the results obtained when comparisons of flow were made with dogs breathing either $21 \%$ oxygen or an hypoxic mixture.

\section{METHODS}

Pulmonary granulomas were produced by injecting complete Freund's adjuvant ${ }^{1}(0.3 \mathrm{ml} / \mathrm{kg})$ into the forepaw vein of a dog on 2 successive days. 3 wk after injection, when the disease had extensively involved the lungs, the dog was studied by cardiac catheterization. This entailed inducing anesthesia with intravenous pentobarbital $(25 \mathrm{mg} / \mathrm{kg})$, intubating the trachea, cannulating a femoral artery, and introducing three catheters : one with its tip in the pulmonary artery, one with its tip in the right atrium, and one with its tip in the inferior vena cava. The first catheter was used for sampling mixed venous blood, the second for injecting dye, and the third for infusing sodium thyamylol, a short-acting anesthetic which facilitated the maintenance of a constant level of anesthesia. With these procedures completed, the dog lay

\footnotetext{
${ }^{1}$ Complete Freund's adjuvant, Difco Labs., Detroit, Mich.
} 
supine on a protective blanket to maintain body temperature. $\mathrm{He}$ received heparin $(100 \mathrm{U} / \mathrm{kg})$ to prevent blood samples from clotting.

The method for inscribing dye curves was similar to that of Theye, Rehder, Quesada, and Fowler (7). As a stock solution, $25 \mathrm{mg}$ of powdered Indocyanine Green was mixed with $14 \mathrm{ml}$ of solvent and $1 \mathrm{ml}$ of human serum albumin. The solution was then drawn into a $20 \mathrm{ml}$ reservoir syringe which was connected through a stopcock to a calibrated spring-loaded Cornwall syringe. For each injection, the Cornwall was filled from the reservoir, then discharged through the catheter.

Standards were prepared by withdrawing $40 \mathrm{ml}$ of blood from the dog, then pipetting $10 \mathrm{ml}$ into each of four test tubes held at $37^{\circ} \mathrm{C}$ in a water bath. The first test tube served as a blank; the remaining three served as standards containing, respectively, 15,25 , and $50 \mu 1$ of the stock solution of dye. The blank and the three standards were drawn through the Gilford densitometer (Gilford Instrument Labs., Inc., Oberlin, Ohio) in sequence, using a Harvard constantspeed withdrawal pump (Harvard Apparatus Co., Millis, Mass.). Upon completion of the calibration, the samples were returned to the dog to minimize the effect of blood loss. With the calibrating points determined, a trial curve was inscribed by injecting a calibrated volume of dye. Afterward, the injected volume was adjusted to insure that the peaks of curves drawn during the study would fall beneath the highest calibrating point. At the end of the study, the densitometer was calibrated again.

To begin the test period, the endotracheal tube was attached to an open breathing circuit consisting of a " $\mathrm{J}$ " valve interposed between a tank of compressed gas and a BenedictRoth spirometer. The dogs breathed either $21 \%$ oxygen or an hypoxic mixture. The latter was $13 \%$ oxygen for the control dogs, and $14 \%$ for the diseased dogs because a preliminary study showed these mixtures gave comparable alveolar oxygen tensions in the two groups. During an equilibration period of $20 \mathrm{~min}$, multiple 1 -min timed ventilations were measured. These served to wash out the breathing apparatus dead space and to provide an index for monitoring the level of anesthesia. The sodium thyamylol drip was regulated so that the inner canthus reflex was present continually and the outer absent. At the end of $20 \mathrm{~min}$, cardiac output measurements were made by the Fick and dye methods in rapid sequence. The Fick measurement entailed drawing simultaneously samples of mixed venous and arterial bloods over a period of about $1 \mathrm{~min}$ while expired gas was collected. The measurements were repeated at 20-min intervals reversing the sequence of Fick and dye determinations on alternate runs until four sets of flows had been obtained.

The blood samples were promptly analyzed for oxygen content and capacity and for carbon dioxide content by the method of Van Slyke and Neill (8). $\mathrm{P}_{\mathrm{CO}_{2}}$ and $\mathrm{pH}$ were measured on an Instrumentation Laboratory Model 311 system (Instrumentation Laboratory, Inc., Lexington, Mass.). Gas samples from the spirometer were analyzed by the Scholander method (9) for concentrations of oxygen and carbon dioxide. Since the densitometer was calíbrated, the blood withdrawn during inscription of the dye curve did not have to be analyzed and could be returned to the dog.

At the conclusion of the study the dog was exsanguinated by transecting the femoral arteries. An autopsy was performed and the position of the catheters confirmed.

Calculations. The Fick cardiac output was calculated from the arteriovenous oxygen difference and the oxygen consumption was measured at the mouth. Values of flow were termed acceptable only when the respiratory quotient for the collection period was between 0.70 and 0.99 , and the minute ventilation during the same period agreed within $15 \%$ of the mean of the serial measurements made during the previous $10 \mathrm{~min}$.

To calculate the dye output, the volume of injectate was taken as the average of five weighings of water expelled from the spring-loaded syringe with the setting used during the study. The calibrations carried out at the beginning and end of the study provided eight calibrating points. With few exceptions the points fell on a straight line. The slope of the line gave the value for converting the area under the inscribed curve to flow. All dye curves were analyzed by the same two investigators, while the Fick flows were independently calculated by two technicians.

Alveolar oxygen tensions were calculated from the standard alveolar air equation.

\section{RESULTS}

To facilitate comparisons, the groups of dogs have been numbered in the following way: group I, five control dogs breathing $21 \% \quad \mathrm{O}_{2}$; group II, five diseased dogs breathing $21 \% \mathrm{O}_{2}$; group III, four control dogs breathing $13 \% \mathrm{O}_{2}$; and group IV, four diseased dogs breathing $14 \% \mathrm{O}_{2}$. The data are presented in Tables I and II.

Respiratory gas exchange. At comparable levels of anesthesia, as judged by the reactivity of the inner and outer canthus reflexes, the mean ventilation $\left(\nabla_{E}\right)$ in the five diseased dogs breathing $21 \%$ oxygen (group II) was $60 \%$ higher than the average for the five control dogs (group I). This difference was highly significant $(t=5.22$, df $=37, P<0.001)$. The increment in ventilation was much larger than could be explained by the $8 \%$ difference in the average rates of oxygen consumption $\left(\mathrm{V}_{\mathrm{O}_{2}}\right)$, so in the diseased dogs the oxygen extraction ratio $\left(\nabla_{\mathbf{O}_{2}} / \nabla_{\mathbf{E}}\right)$ was low.

Calculated alveolar oxygen tension and blood gas composition. During the inhalation of $21 \%$ oxygen, the alveolar oxygen tension was the same in the control (group I) and diseased (group II) dogs. While the hyperventilation of the diseased animals produced normal alveolar tensions of oxygen, the mean arterial oxygen saturation was $88 \%$ compared with the value of $92 \%$ in the controls.

During hypoxia, the alveolar oxygen tensions were the same in the control (group III) and diseased (group IV) dogs with an approximate correspondence in arterial oxygen saturations.

Fick and dye flows. The paired Fick and dye flows measured in the control dogs agreed well, regardless of the inspired oxygen concentration. When the difference between each paired measurement was expressed as a percentage of the Fick value, the average difference was less than $1 \%$ in both the eupoxic (group I) and hypoxic (group III) animals. By way of contrast, the average value for Fick flow was $12 \%$ higher than the average for dye flow in the diseased dogs breathing $21 \%$ oxygen (group II). When compared to the control animals of 
TABLE I

Gas Exchange, Blood Gas Composition, and Blood Flows Determined while Normal and Diseased Dogs Breathed 21\% $\mathrm{O}_{2}^{*}$

\begin{tabular}{|c|c|c|c|c|c|c|c|c|c|c|c|c|}
\hline $\begin{array}{l}\text { Dog } \\
\text { No. }\end{array}$ & $\begin{array}{l}\text { Run } \\
\text { No. }\end{array}$ & $\dot{\mathbf{V}}_{\mathbf{E}}$ & $\dot{\mathrm{V}}_{2}$ & $\mathbf{R}$ & $\mathrm{PaCO}_{2}$ & $\mathrm{CaO}_{2}$ & $\mathrm{CaO}_{2}-\mathrm{C} \overline{\mathrm{v}}_{2}$ & $\mathrm{CAPO}_{2}$ & $\mathrm{SaO}_{2}$ & $\mathrm{PAO}_{2}$ & $\dot{Q}_{\text {mat }}$ & Q́Dy• \\
\hline & & $\underset{\text { per } k g}{m l / m i n}$ & $\underset{\text { per } k g}{m l / m i n}$ & & $m m H g$ & $\begin{array}{c}m l / 100 \\
m l\end{array}$ & $\begin{array}{c}m l / 100 \\
m l\end{array}$ & $\begin{array}{c}m l / 100 \\
m l\end{array}$ & $\%$ & $m m H g$ & $\underset{\text { per } k g}{\operatorname{ml} / \min }$ & $\underset{\text { per } k g}{\operatorname{ml} / \min }$ \\
\hline \multicolumn{13}{|c|}{ Group I, normal dogs } \\
\hline \multirow[t]{4}{*}{1591} & 1 & 273 & 6.5 & 0.89 & 27 & 17.2 & 5.9 & 17.6 & 97 & 120 & 110 & 126 \\
\hline & 2 & 305 & 6.7 & 0.92 & 26 & 17.8 & 6.0 & 17.8 & 99 & 122 & 111 & 121 \\
\hline & 3 & 290 & 6.7 & 0.90 & 25 & 17.8 & 6.0 & 18.5 & 95 & 123 & 112 & 105 \\
\hline & 4 & 315 & 7.6 & 0.82 & 25 & 17.8 & 8.0 & 18.4 & 96 & 121 & 95 & 95 \\
\hline \multirow[t]{4}{*}{1544} & 1 & 240 & 5.8 & 0.96 & 38 & 16.0 & 3.3 & 17.8 & 89 & 111 & 176 & 178 \\
\hline & 2 & 209 & 5.5 & 0.88 & 38 & 16.6 & 2.6 & 18.4 & 89 & 108 & 205 & 188 \\
\hline & 3 & 227 & 5.6 & 0.94 & 38 & 17.0 & 3.6 & 18.6 & 90 & 110 & 156 & 144 \\
\hline & 4 & 240 & 6.0 & 0.91 & 36 & 16.8 & 4.5 & 18.7 & 89 & 111 & 135 & 127 \\
\hline \multirow[t]{4}{*}{446} & 1 & 333 & 6.4 & 0.88 & 44 & 19.5 & 3.7 & 21.3 & 91 & 101 & 174 & 163 \\
\hline & 2 & 337 & 6.0 & 0.87 & 43 & 20.0 & 3.3 & 21.8 & 86 & 102 & 180 & 197 \\
\hline & 3 & 326 & 5.9 & 0.90 & 45 & 20.8 & 3.7 & 22.8 & 90 & 101 & 160 & 153 \\
\hline & 4 & 349 & 6.9 & 0.87 & 45 & 20.8 & 3.7 & 22.7 & 91 & 100 & 186 & 165 \\
\hline \multirow[t]{4}{*}{1589} & 1 & 200 & 5.7 & 0.85 & 37 & 17.5 & 3.5 & 19.7 & 88 & 108 & 162 & 199 \\
\hline & 2 & 306 & 7.9 & 0.94 & 35 & 19.2 & 3.9 & 20.2 & 94 & 110 & 203 & 214 \\
\hline & 3 & 238 & 6.3 & 0.87 & 35 & 19.4 & 4.1 & 20.5 & 94 & 111 & 154 & 155 \\
\hline & 4 & 233 & 6.4 & 0.87 & 34 & 18.6 & 4.6 & 20.3 & 91 & 112 & 139 & 134 \\
\hline \multirow[t]{4}{*}{406} & 1 & 167 & 5.3 & 0.89 & 37 & 16.7 & 4.5 & 18.1 & 91 & 109 & 117 & 129 \\
\hline & 2 & - & - & - & - & - & - & - & - & - & - & - \\
\hline & 3 & 194 & 5.8 & 0.91 & 32 & 18.9 & 4.4 & 20.2 & 93 & 115 & 131 & 142 \\
\hline & 4 & 199 & 6.3 & 0.88 & 31 & 19.3 & 6.3 & 20.2 & 95 & 116 & 99 & 91 \\
\hline \multicolumn{2}{|l|}{ Mean } & 262 & 6.3 & 0.89 & 35 & 18.3 & 4.5 & 19.7 & 92 & 111 & 148 & 149 \\
\hline \multicolumn{13}{|c|}{ Group II, diseased dogs } \\
\hline \multirow[t]{4}{*}{1556} & 1 & 336 & 6.7 & 0.80 & 34 & 18.6 & 3.8 & 19.9 & 92 & 109 & 176 & 166 \\
\hline & 2 & 387 & 6.7 & 0.83 & 31 & 18.3 & 3.7 & 20.0 & 91 & 114 & 180 & 158 \\
\hline & 3 & 347 & 6.3 & 0.87 & 32 & 17.5 & 3.4 & 19.9 & 87 & 114 & 184 & 120 \\
\hline & 4 & 345 & 6.0 & 0.81 & 32 & 17.8 & 5.4 & 19.9 & 88 & 112 & 112 & 113 \\
\hline \multirow[t]{4}{*}{1587} & 1 & 297 & 5.3 & 0.87 & 34 & 16.7 & 2.8 & 17.6 & 94 & 112 & 190 & 178 \\
\hline & 2 & 233 & 5.4 & 0.81 & 38 & 17.8 & 2.5 & 18.5 & 95 & 105 & 215 & 183 \\
\hline & 3 & 256 & 5.4 & 0.86 & 35 & 18.4 & 3.0 & 18.7 & 97 & 110 & 179 & 138 \\
\hline & 4 & 260 & 5.3 & 0.88 & 34 & 18.4 & 4.2 & 18.7 & 97 & 112 & 127 & 121 \\
\hline \multirow[t]{4}{*}{511} & 1 & 527 & 7.8 & 0.76 & 30 & 15.3 & 3.9 & 19.8 & 76 & 112 & 200 & 177 \\
\hline & 2 & 611 & 8.9 & 0.75 & 34 & 14.6 & 3.8 & 19.4 & 74 & 107 & 234 & 181 \\
\hline & 3 & 492 & 7.6 & 0.78 & 33 & 14.6 & 4.8 & 18.6 & 77 & 108 & 157 & 161 \\
\hline & 4 & 576 & 8.3 & 0.77 & 36 & 14.3 & 4.6 & 18.7 & 75 & 108 & 180 & 154 \\
\hline \multirow[t]{4}{*}{471} & 1 & 519 & 7.5 & 0.95 & 26 & 15.8 & 5.6 & 16.1 & 97 & 123 & 134 & 125 \\
\hline & 2 & 575 & 7.6 & 0.96 & 25 & 16.4 & 5.2 & 17.2 & 94 & 124 & 146 & 135 \\
\hline & 3 & 574 & 7.5 & 0.96 & 32 & 16.0 & 4.6 & 17.2 & 92 & 119 & 163 & 117 \\
\hline & 4 & 609 & 7.3 & 0.96 & 34 & 16.7 & 6.0 & 17.8 & 93 & 115 & 123 & 107 \\
\hline \multirow[t]{4}{*}{441} & 1 & 437 & 6.6 & 0.89 & 27 & 17.6 & 4.7 & 19.1 & 91 & 120 & 140 & 133 \\
\hline & 2 & 391 & 6.3 & 0.85 & 28 & 16.3 & 5.7 & 19.0 & 85 & 118 & 111 & 102 \\
\hline & 3 & 368 & 6.2 & 0.85 & 34 & 15.6 & 6.1 & 18.5 & 83 & 111 & 102 & 90 \\
\hline & 4 & 379 & 6.4 & 0.84 & 36 & 15.1 & 6.4 & 18.5 & 81 & 109 & 100 & 88 \\
\hline Mean & & 426 & 6.8 & 0.85 & 32 & 16.6 & 4.5 & 18.6 & 88 & 113 & 158 & 137 \\
\hline
\end{tabular}

* The symbols used in Tables I and II are defined as follows: $\dot{V}_{E}$, volume of gas expired per minute (BTPS); $\dot{V}_{O_{2}}$, volume of oxygen taken up per minute (STPD); $\mathrm{R}$, respiratory exchange ratio; $\mathrm{Pa}_{\mathrm{CO}_{2}}$, arterial blood carbon dioxide tension; $\mathrm{Ca}_{2}$, arterial blood oxygen content; $\mathrm{C}_{\mathrm{O}_{2}}$, mixed venous blood oxygen content; $\mathrm{CAPO_{2 }}$, arterial blood oxygen capacity; $\mathrm{S}_{\mathrm{O}_{2}}$, arterial blood oxygen saturation; $\mathrm{PAO}_{2}$, calculated alveolar oxygen tension; $\dot{\mathrm{Q}}_{\mathrm{rick}}$, blood flow according to Fick

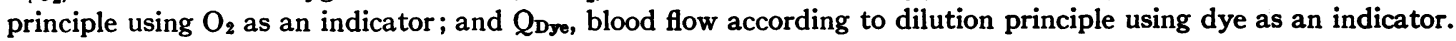


TABLE II

Gas Exchange, Blood Gas Composition, and Blood Flows Determined while Normal and Diseased Dogs Breathed Hypoxic Mixtures

\begin{tabular}{|c|c|c|c|c|c|c|c|c|c|c|c|c|}
\hline $\begin{array}{l}\text { Dog } \\
\text { No. }\end{array}$ & $\begin{array}{l}\text { Run } \\
\text { No. }\end{array}$ & $\dot{\mathrm{V}}_{\mathbf{E}}$ & $\dot{\mathrm{V}}_{\mathbf{2}}$ & $\mathbf{R}$ & $\mathrm{PaCO}_{2}$ & $\mathrm{CaO}_{2}$ & $\mathrm{CaO}_{2}-\mathrm{Cv}_{\mathrm{O}_{2}}$ & CAP & $\mathrm{SaO}_{2}$ & $\mathrm{PAO}_{2}$ & $\dot{Q}_{\text {Fick }}$ & $\dot{Q} \mathbf{D y}_{\mathbf{y}}$ \\
\hline & & $\underset{\mathrm{per} / \mathrm{kg}}{\mathrm{ml} / \mathrm{min}}$ & $\underset{\text { per } k \mathrm{~kg}}{\mathrm{ml} / \mathrm{m}}$ & & $m m H g$ & $\begin{array}{c}m l / 100 \\
m l\end{array}$ & $\underset{m l / 100}{m l}$ & $\underset{m l / 100}{m l}$ & $\%$ & $m m H g$ & $\underset{\mathrm{per} / \mathrm{kg}}{\mathrm{ml}}$ & $\begin{array}{c}\mathrm{ml} / \mathrm{min} \\
\mathrm{per} \mathrm{kg}\end{array}$ \\
\hline \multicolumn{13}{|c|}{ Group III, normal dogs breathing $13 \% \mathrm{O}_{2}$} \\
\hline \multirow[t]{4}{*}{$1554^{\circ}$} & 1 & 428 & 8.5 & 0.86 & 35 & 17.0 & 4.0 & 20.6 & 82 & 60 & 213 & 241 \\
\hline & 2 & 404 & 7.1 & 0.85 & 33 & 18.4 & 3.3 & 22.3 & 82 & 62 & 216 & 219 \\
\hline & 3 & 324 & 7.0 & 0.81 & 33 & 18.0 & 3.5 . & 21.4 & 83 & 60 & 200 & 162 \\
\hline & 4 & 422 & 8.0 & 0.84 & 30 & 18.8 & 4.4 & 21.8 & 85 & 65 & 181 & 162 \\
\hline \multirow[t]{4}{*}{1590} & 1 & 293 & 6.0 & 0.87 & 35 & 15.4 & 4.4 & 18.2 & 84 & 60 & 137 & 172 \\
\hline & 2 & 323 & 6.3 & 0.85 & 31 & 15.9 & 4.2 & 18.1 & 87 & 64 & 150 & 137 \\
\hline & 3 & 296 & 6.2 & 0.84 & 31 & 15.2 & 4.3 & 19.1 & 79 & 64 & 144 & 109 \\
\hline & 4 & 327 & 5.5 & 0.96 & 31 & 15.7 & 4.7 & 18.6 & 82 & 68 & 118 & 108 \\
\hline \multirow{4}{*}{355} & 1 & 287 & 5.2 & 0.92 & 38 & 14.8 & 5.5 & 18.8 & 78 & 61 & 94 & 116 \\
\hline & 2 & 293 & 5.3 & 0.89 & 34 & 15.9 & 6.4 & 18.8 & 84 & 72 & 83 & 103 \\
\hline & 3 & 302 & 4.9 & 0.94 & 32 & 15.5 & 4.9 & 18.4 & 83 & 72 & 100 & 94 \\
\hline & 4 & 297 & 4.7 & 0.99 & 30 & 15.9 & 6.4 & 18.8 & 84 & 72 & 72 & 85 \\
\hline \multirow[t]{4}{*}{503} & 1 & 500 & 7.2 & 0.90 & 26 & 13.7 & 4.7 & 15.6 & 81 & 71 & 152 & 148 \\
\hline & 2 & 439 & 6.7 & 0.91 & 27 & 14.3 & 4.5 & 18.0 & 78 & 71 & 149 & 156 \\
\hline & 3 & 385 & 6.4 & 0.89 & 26 & 15.7 & 4.4 & 19.0 & 82 & 71 & 146 & 135 \\
\hline & 4 & 403 & 6.4 & 0.94 & 24 & 16.1 & 5.0 & 19.0 & 84 & 75 & 128 & 123 \\
\hline \multicolumn{2}{|l|}{ Mean } & 358 & 6.3 & 0.89 & 31 & 16.0 & 4.7 & 19.2 & 82 & 67 & 143 & 142 \\
\hline \multicolumn{13}{|c|}{ Group IV, diseased dogs breathing $14 \% \mathrm{O}_{2}$} \\
\hline \multirow[t]{4}{*}{457} & 1 & 256 & 5.1 & 0.96 & 31 & 16.6 & 2.4 & 20.1 & 82 & 68 & 213 & 187 \\
\hline & 2 & 268 & 5.8 & 0.94 & 30 & 17.8 & 3.4 & 21.8 & 81 & 68 & 169 & 194 \\
\hline & 3 & 260 & 5.4 & 0.92 & 30 & 18.6 & 3.2 & 22.1 & 83 & 68 & 170 & 181 \\
\hline & 4 & 276 & 5.5 & 0.93 & 25 & 19.1 & 3.5 & 21.9 & 86 & 73 & 156 & 167 \\
\hline \multirow[t]{4}{*}{465} & 1 & 768 & 7.9 & 0.90 & 21 & 22.0 & 5.3 & 24.3 & 90 & 76 & 149 & 178 \\
\hline & 2 & 597 & 7.3 & 0.85 & 23 & 21.1 & 5.0 & 23.3 & 90 & 74 & 145 & 142 \\
\hline & 3 & 509 & 6.7 & 0.83 & 21 & 20.5 & 5.6 & 23.3 & 87 & 75 & 119 & 119 \\
\hline & 4 & 480 & 6.3 & 0.84 & 23 & 20.5 & 6.5 & 22.2 & 91 & 73 & 98 & 111 \\
\hline \multirow[t]{4}{*}{470} & 1 & 484 & 5.9 & 0.88 & 26 & 19.7 & 4.2 & 22.3 & 87 & 71 & 141 & 139 \\
\hline & 2 & 501 & 6.1 & 0.89 & 23 & 22.7 & 5.4 & 24.7 & 91 & 74 & 112 & 122 \\
\hline & 3 & 484 & 5.9 & 0.91 & 22 & 22.3 & 4.5 & 24.5 & 90 & 76 & 131 & 110 \\
\hline & 4 & 491 & 5.8 & 0.86 & 22 & 22.2 & 5.0 & 24.5 & 82 & 75 & 116 & 94 \\
\hline \multirow[t]{4}{*}{535} & 1 & 489 & 6.3 & 0.85 & 36 & 15.6 & 4.9 & 20.5 & 75 & 59 & 129 & 116 \\
\hline & 2 & 503 & 6.2 & 0.84 & 32 & 15.9 & 4.5 & 20.6 & 76 & 63 & 137 & 127 \\
\hline & 3 & 454 & 6.2 & 0.81 & 29 & 16.9 & 4.4 & 20.9 & 80 & 65 & 140 & 122 \\
\hline & 4 & - & - & - & - & - & - & - & - & - & - & - \\
\hline Mean & & 455 & 6.2 & 0.88 & 26 & 19.4 & 4.5 & 22.5 & 85 & 71 & 142 & 141 \\
\hline
\end{tabular}

group I, this difference was significant $(t=3.75$, $\mathrm{df}=$ $37, P<0.001)$. On the other hand, the administration of $14 \%$ oxygen to diseased dogs (group IV) restored the agreement between the Fick and dye flows.

\section{DISCUSSION}

The dissociation between ventilation and oxygen consumption in the diseased dogs resembles that found in patients with diffuse pulmonary disease (10). Further, the low arterial oxygen saturation in the face of hyperventilation is similar to that seen in humans with granulomatous processes in the lung.

The discrepancy between the Fick and dye flows in the diseased dogs also resembles observations made in man. $(11,12)$. In the human studies, the difference seemed best explained by an intrapulmonary utilization

1314 P. R. B. Caldwell, U. Echeverri, M. M. Kilcoyne, and H. W. Fritts, Jr. 
of oxygen. However, other possibilities merit consideration. First, a systematic error might have affected the measurements made in any one of the four groups. But since studies on normal and diseased dogs were performed in random sequence, such an error seems unlikely. Second, a factor which might cause the flows to diverge would be a vascular adhesion carrying venous blood from the chest wall or other extrapulmonary structures into the vessels of the lung. Whereas this possibility could not be ruled out in the studies of patients, autopsies of the dogs did not reveal adhesions. A third factor, resembling the second, is an augmentation of thebesian flow in the diseased eupoxic dogs. While our data do not exclude this possibility, there is no reason to invoke such a change. Finally, an unidentified factor could cause the dye flow to be falsely low. This appears to be unlikely in view of our experience with human lung disease. Studies in patients with diffuse nonobstructive pulmonary disease showed the dye measurement agreed with that obtained with the inert gas $\mathrm{Kr}^{8}$, and both were lower than the Fick value. In addition, the possibility that abnormalities in distribution of flow through the lung might systematically lower the dye flow seemed to be ruled out when good agreement between Fick and dye flows was found in a group of patients with chronic obstructive lung disease. ${ }^{2}$ In view of these considerations, then, the most likely cause for the difference between the flows in the present study appears to be the oxygen metabolized by the diseased lung tissues.

Using the calculation previously published (11), we converted the measured values of flow, concentration, and uptake to intrapulmonary oxygen consumptions. At a mean alveolar oxygen tension of $110 \mathrm{~mm} \mathrm{Hg}$, the lungs of the diseased dogs appeared to utilize about $12 \%$ of the oxygen consumed by the body, whereas at a mean alveolar tension of $70 \mathrm{~mm} \mathrm{Hg}$, the apparent utilization disappeared. The methods are not sufficiently precise to give weight to the $12 \%$ as an absolute value. Even so, considerable evidence from in vitro studies suggests that diffuse pulmonary disease could increase the oxygen utilization of the lung toward this range. For example, Strauss demonstrated that tuberculous pulmonary tissue had a metabolic rate more than twice that of normal human lung, and malignant tissue had a fourfold greater oxygen consumption (13). Also, the tissue mass of the lung is increased by the presence of the abnormal cells.

By combining the observations of flow with those made on $A-\bar{V}$ differences of lactate (6), one discerns the following pattern: at normal alveolar oxygen tensions the diseased lung appears to consume oxygen, whereas under hypoxia the oxygen utilization diminishes and a

\footnotetext{
${ }^{2}$ Fritts, H. W., Jr. Unpublished observations.
}

positive $A-\bar{V}$ difference of lactate develops. Thus, the hypothesis mentioned in the Introduction does not hold for lungs with diffuse disease. Contrary to the earlier argument, the Fick and dye outputs agree when there is a measurable $A-\bar{V}$ difference of lactate and diverge when no difference exists.

\section{ACKNOWLEDGMENTS}

Dr. Caldwell was a Senior Research Fellow of the New York Heart Association and is currently a Career Investigator of the New York City Health Research Council. Dr. Echeverri was a trainee of the United States Public Health Service.

This work was supported by Grants HE-02001, HE-5443, and HE-05741 from the National Heart Institute, United States Public Health Service.

\section{REFERENCES}

1. Mitchell, A. M., and A. Cournand. 1955. The fate ot circulating lactic acid in the human lung. J. Clin. Invest. 34: 471 .

2. Halmágyi, D., A. Reinhold, B. Felkai, and J. Iványi. 1951. Zur frage der intrapulmonalen Milchsaureoxydation beim Menschen. Klin. Wochenschr. 29: 219.

3. Beickert, A., and W. Braun. 1956. Das Verhalten der Milchsauere in der menschlichen Lunge bei Luft-und Sauerstoffatmung. Klin. Wochrenschr. 34: 246.

4. Eisfeld, G., and H. Julich. 1956. Das Verhalten des Milchsaure-, Brenztraubensaure-sowie Zitronensaurespiegels in Lungenkreislauf. Z. Kreislaufforsch. 45: 874.

5. Harris, P., T. Bailey, M. Bateman, M. G. Fitzgerald, J. Gloster, E. A. Harris, and K. W. Donald. 1963. Lactate, pyruvate, glucose, and free fatty acid in mixed venous and arterial blood. J. Appl. Physiol. 18: 933.

6. Strauss, B., P. R. B. Caldwell, and H. W. Fritts, Jr. 1969. Observations on a model of proliferative lung disease. I. Transpulmonary arteriovenous differences of lactate, pyruvate, and glucose. J. Clin. Invest. 49: 1305.

7. Theye, R. A., K. Rehder, R. S. Quesada, and W. S. Fowler. 1964. Measurement of cardiac output by an indicator-dilution method. Anesthesiology. 25: 71.

8. Van Slyke, D. D., and J. M. Neill. 1924. The determination of gases in blood and other solutions by vacuum extraction and manometric measurement. J. Biol. Chem. 61: 523.

9. Scholander, P. F. 1947. Analyzer for accurate estimation of respiratory gases in one-half cubic centimeter samples. J. Biol. Chem. 167: 235.

10. Baldwin, E. deF., A. Cournand, and D. W. Richards, Jr. 1949. Pulmonary insufficiency. II. A study of thirty nine cases of pulmonary fibrosis. Medicine. 28: 1 .

11. Fritts, H. W., Jr., D. W. Richards, and A. Cournand. 1961. Oxygen consumption of tissues in the human lung. Science (Washington). 133: 1070.

12. Fritts, H. W., Jr., B. Strauss, W. Wichern, Jr., and A. Cournand. 1963. Utilization of oxygen in the lungs of patients with diffuse, non-obstructive pulmonary disease. Trans. Ass. Amer. Physicians Philadelphia. 76: 302.

13. Strauss, B. 1964. In vitro respiration of normal and pathologic human lung. J. Appl. Physiol. 19: 503. 